\title{
Anterior pericardial tracheoplasty for long-segment tracheal stenosis: Long-term outcomes
}

\author{
Nervin Fanous, MD, ${ }^{a}$ S. Adil Husain, MD, ${ }^{b}$ Mark Ruzmetov, MD, PhD, ${ }^{a}$ Mark D. Rodefeld, MD, \\ Mark W. Turrentine, MD, and John W. Brown, MD ${ }^{\mathrm{a}}$
}

\begin{abstract}
Objective: Although several techniques have been described for the treatment of tracheal stenosis, including slide tracheoplasty, tracheal autograft, rib grafting, and use of a pericardial patch, the optimal repair remains controversial because of a lack of long-term follow-up data. The purpose of this study is to examine the long-term results of anterior pericardial tracheoplasty.
\end{abstract}

\begin{abstract}
Methods: To assess the long-term outcomes of patients who underwent repair of tracheal stenosis with anterior pericardial tracheoplasty, we reviewed the case histories of 26 consecutive patients (1984-present). All but 5 had long-segment tracheal stenosis with more than 10 complete tracheal rings. Twenty-one had significant cardiac disease, and 10 had their cardiac lesions repaired at the time of their tracheoplasty. The median age was 6 months (range, 2 days-25 years). All patients underwent anterior pericardial tracheoplasty through a median sternotomy during normothermic cardiopulmonary bypass. We have previously described our tracheoplasty technique. An average of 14 tracheal rings (range, 5-22) was divided anteriorly, and a patch of fresh autologous pericardium was used to enlarge the trachea to 1.5 times the predicted diameter for age and weight.

Results: There were 3 hospital deaths (at 1, 2, and 7 months, respectively) and 2 late deaths (at 2 and 13 years postoperatively, respectively). No deaths were related to airway obstruction. Two survivors required tracheostomy postoperatively, one after formation of granulation tissue and stenosis and the other after failure to wean from mechanical ventilation. All survivors remain asymptomatic, with minimal to no evidence of airway obstruction. Median follow-up is 11 years (range, 3 months-22 years).
\end{abstract}

Conclusion: Anterior pericardial tracheoplasty for tracheal stenosis provides excellent results in the majority of patients at long-term follow-up. (J Thorac Cardiovasc Surg 2010;139:18-25)

Long-segment tracheal stenosis in infants and children is rare but is the most frequent congenital tracheal anomaly requiring operative intervention. Congenital tracheal stenosis is typified by the presence of complete tracheal rings. Complete tracheal rings (or $\mathrm{O}$ rings) are always smaller than normal C-shaped rings and can severely compromise a child's airway. Although some children with complete rings will have a large enough airway not to need surgical intervention, more than $80 \%$ will need an operation to correct the stenosis. The mortality rate with medical management is prohibitively high. ${ }^{1}$ Various surgical treatment options have evolved over the last 25 years. Kimura and colleagues $^{2}$ performed the first successful intervention for long-segment tracheal stenosis in 1982 using rib cartilage tracheoplasty. Use of pericardial patch tracheoplasty was

From the Section of Cardiothoracic Surgery, ${ }^{\mathrm{a}}$ Indiana University School of Medicine, Indianapolis, Ind; and the Section of Cardiothoracic Surgery, ${ }^{\mathrm{b}}$ University of Texas Health Sciences Center, San Antonio, Tex.

Read at the Thirty-third Annual Meeting of the Western Thoracic Surgical Association, Santa Ana Pueblo, NM, June 27-30, 2007.

Received for publication July 3, 2007; revisions received Sept 8, 2009; accepted for publication Sept 21, 2009; available ahead of print Nov 12, 2009.

Address for reprints: John W. Brown, MD, Section of Cardiothoracic Surgery, Indiana University School of Medicine, 545 Barnhill Dr, EH 215, Indianapolis, IN $46202-$

5123 (E-mail: jobrown@iupui.edu).

$0022-5223 / \$ 36.00$

Copyright (c) 2010 by The American Association for Thoracic Surgery

doi:10.1016/j.jtcvs.2009.09.040 first described in 1984 by Idriss and associates. ${ }^{3}$ We have used a similar technique, which has been previously described. Various other methods, including tracheal resection, slide tracheoplasty, and tracheal autograft, have also been described. Because of the rarity of this disease, there are limited long-term outcome data for the various described techniques.

\section{MATERIALS AND METHODS}

Between November 1984 and July 2006, 26 patients (age, 28 weeks' gestation to 25 years) were referred to James Whitcomb Riley Hospital for Children with life-threatening respiratory distress caused by long-segment tracheal stenosis secondary to incomplete tracheal rings. Twentyone $(81 \%)$ patients had associated cardiac lesions. These lesions included isolated and combined lesions, including patent ductus arteriosus, ventricular septal defect, atrial septal defect, pulmonary artery sling, tetralogy of Fallot, and atrioventricular canal. Seven (27\%) patients also exhibited other tracheobronchial anomalies, including anomalous right upper lobe takeoff, sequestration, pulmonary agenesis, and pulmonary hypoplasia.

The stenosis involved 5 to 22 complete rings (mean, 14 tracheal rings) in all patients. Twenty-one patients presented with respiratory distress, 3 patients presented with inability to be weaned from mechanical ventilation, 1 patient presented with recurrent pneumonias, and 1 patient presented with shortness of breath 25 years after tracheostomy.

Nineteen patients required mechanical intubation before tracheoplasty. Of these, 5 had a prior tracheostomy. One patient was started on extracorporeal membrane oxygenation preoperatively as a result of prematurity and hyaline membrane disease; however, no patients required extracorporeal membrane oxygenation postoperatively.

Fiberoptic and rigid bronchoscopy and microlaryngoscopy were the principal methods used for evaluating tracheal stenosis preoperatively, 
intraoperatively, and postoperatively. Endoscopy was performed once postoperatively unless the patient had any evidence of airway compromise. Functional data, such as spirometric data, were not obtained routinely. Computed tomographic and echocardiographic analyses were essential in the evaluation of associated cardiovascular anomalies.

\section{Operative Technique}

Details of our operative technique have been previously described. ${ }^{4}$ A median sternotomy was performed, and the thymus was either divided or resected. The pericardium was opened, and the innominate vessels were mobilized. The anterior trachea was then exposed from the cricoid to the carina. The lateral blood supply to the trachea and recurrent laryngeal nerves was not disturbed. Heparin was injected, and patients were cannulated through the right atrium and ascending aorta. Normothermic cardiopulmonary bypass was instituted, and the endotracheal tube was removed. Fiberoptic bronchoscopy was used to confirm the degree and extent of stenosis. The trachea was incised in the midline the length of the stenotic segment. One normal ring was opened superiorly and inferiorly to ensure complete relief of obstruction (Figure 1).

A piece of fresh pericardium was harvested and tailored to enlarge the luminal diameter to approximately 1.5 times the predicted, age-adjusted diameter. ${ }^{5}$ The pericardium was sutured to the tracheal edge with continuous, running, 6-0 polydioxanone sutures (Ethicon, Inc, Somerville, NJ).

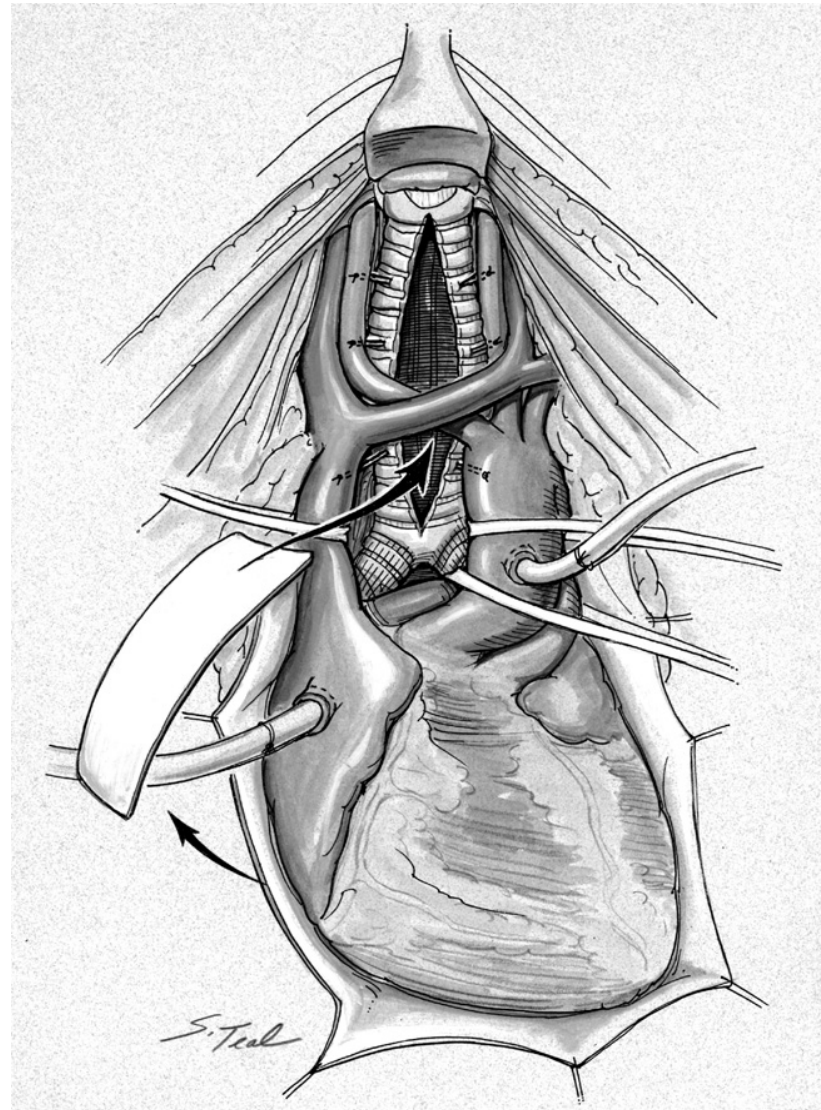

FIGURE 1. Anterior pericardial tracheoplasty was performed through a median sternotomy during partial normothermic cardiopulmonary bypass. Three to 4 tacking sutures were placed to prevent future tracheomalacia from recoil, and harvested fresh autologous pericardium was tailored to enlarge the tracheal lumen to 1.5 times the predicted diameter.
Care was taken to avoid the tracheal mucosa, therefore reducing the nidus formation for granulation tissue development (Figure 2).

Interrupted sutures were placed superficially on the pericardial patch, tacking it to surrounding mediastinal structures and thereby suspending the patch (Figure 3).

The tracheal edges were also stented open by tacking the edges to nearby structures, thereby decreasing the likelihood of potential recoil (Figure 4). At this point, the endotracheal tube was reinserted, and airway pressure was increased to $35 \mathrm{~mm} \mathrm{Hg}$ under water to confirm an airtight anastomosis. The endotracheal tube was reinserted under direct visualization, with the tip at the level of the midpatch and the Murphy eye of the endotracheal tube facing posteriorly. Cardiopulmonary bypass was then weaned, heparin was reversed, and the sternotomy was closed over a drain.

\section{Postoperative Care}

All patients were kept paralyzed, sedated, and intubated for at least 6 to 14 days to allow pericardial patch adherence to surrounding pericardial structures. Before attempted extubation, the airway was evaluated by means of fiberoptic bronchoscopy. If the patch appeared to be immobile and the airway was otherwise patent, paralysis was discontinued and the patient was allowed to awaken and breathe spontaneously before a trial of extubation. Granulation tissue, if present, was removed by means of rigid bronchoscopy.

\section{RESULTS}

A mean of 14 rings (range, 5-22) were divided. The mean age at the time of the operation was 22 months, and the median age was 6 months (range, 2 days -25 years). Of the

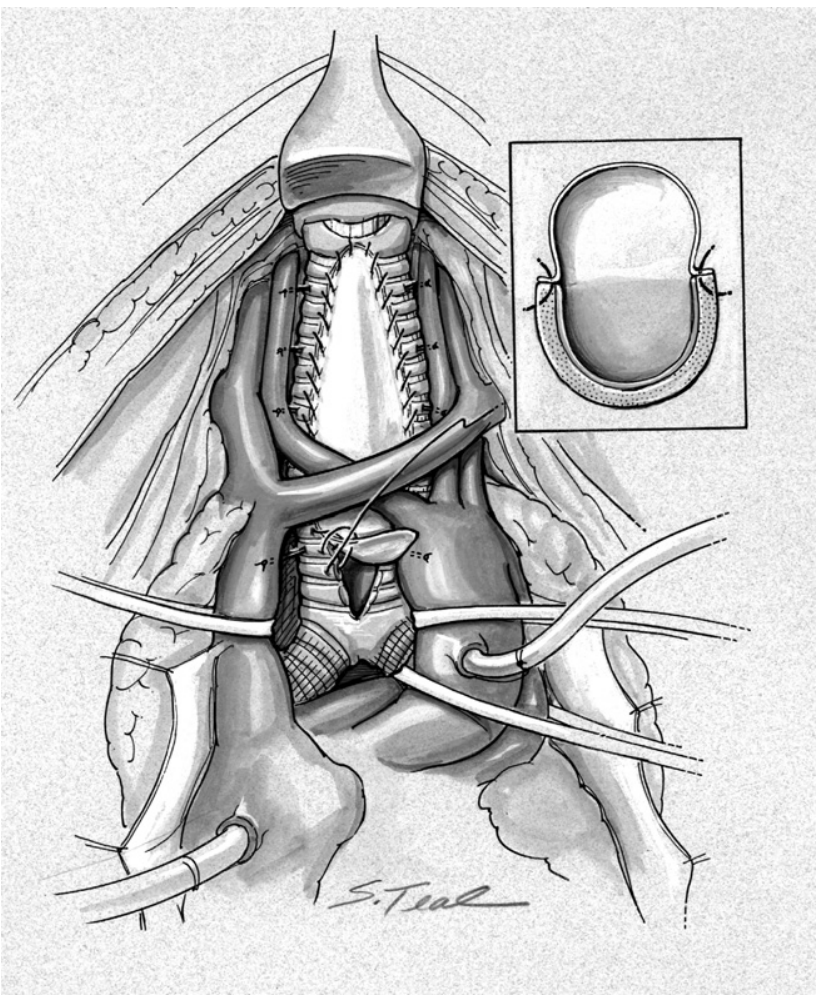

FIGURE 2. The pericardium was sutured to the tracheal edge with a continuous running 6-0 polydioxanone suture. Care was taken to avoid exposure of any suture material to the lumen of the airway in an attempt to minimize the subsequent formation of granulation tissue. 


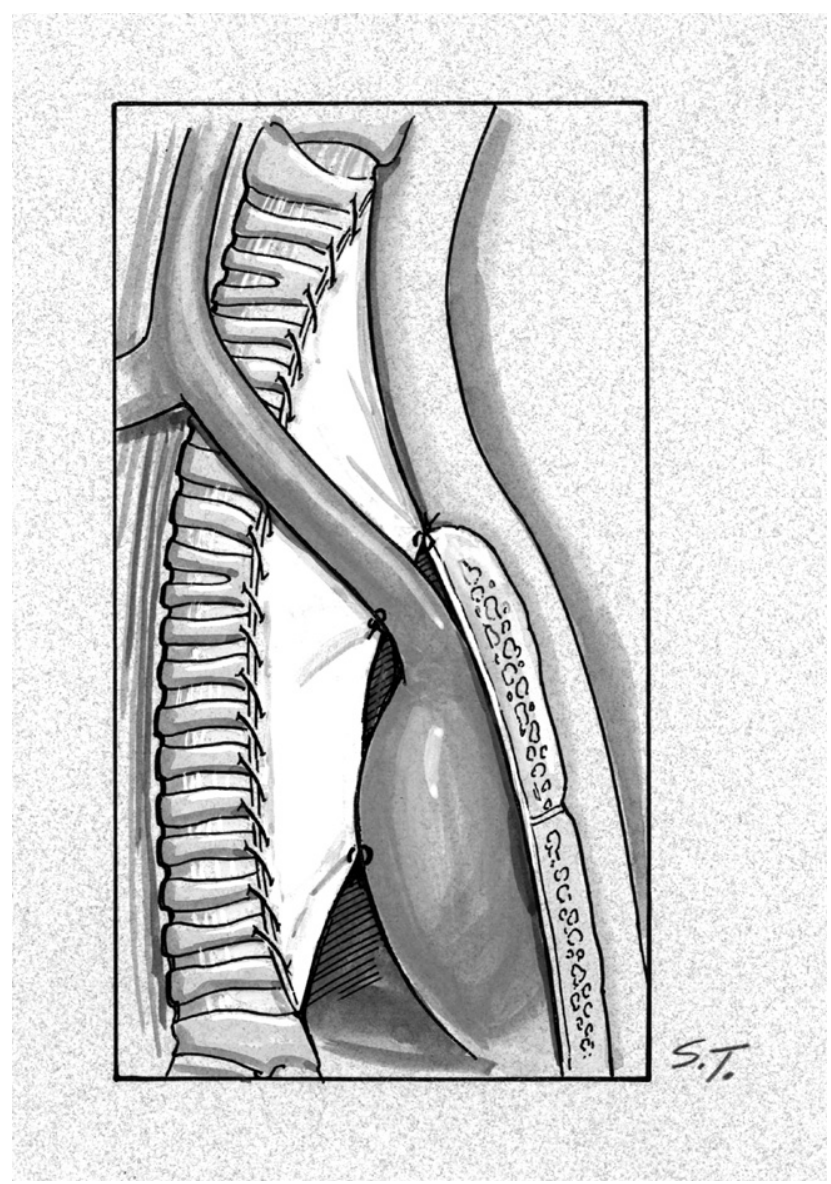

FIGURE 3. Several tacking sutures were used to suspend the pericardium anteriorly to the surrounding mediastinal structures.

26 patients, as of this date, 16 are known to be alive and well. Of this group, the mean follow-up is 8.8 years (range, 11 months-19 years). Five patients were asymptomatic when lost to follow-up after a mean of 6 years (range, 5.5-7 years).

The median number of days intubated was 14 (range, 6-379 days). Median hospital stay was 17 days (range, 10-396 days).

Of the 26 patients, $10(38 \%)$ had some degree of granulation tissue on postoperative surveillance bronchoscopy. In all cases the granulation tissue was removed during rigid or fiberoptic bronchoscopy. In one case the patient required a tracheostomy 5 months postoperatively for stenosis and exuberant granulation tissue at the distal tracheal incision. This patient underwent approximately 30 airway procedures over the course of 16 years to treat a combination of tracheal stenosis and granulation tissue. In another patient there was a distal narrowing of the trachea past the pericardial patch. A tracheostomy was placed 1 year postoperatively. This patient did have granulation tissue associated with the tracheostomy tube and involving the vocal cords. He has undergone multiple bronchoscopies over the course of 7 years to manage his airway. In the remaining 8 cases, gran-

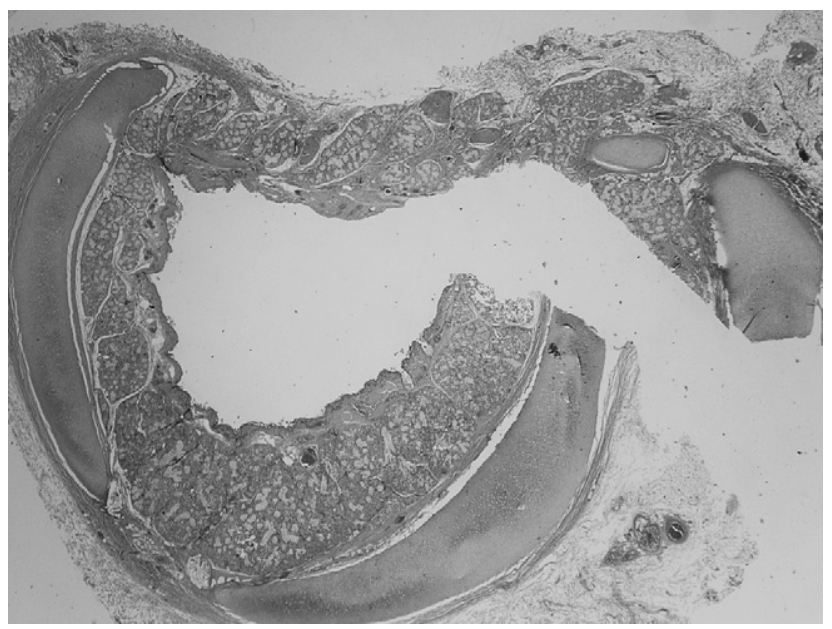

FIGURE 4. Postmortem tracheal analysis depicting incorporation of pericardial patch: horizontal section of the trachea showing the improved tracheal lumen.

ulation tissue was removed during the initial bronchoscopy, and no further intervention was required.

Two patients required redo pericardial tracheoplasty. One patient (no. 2 in the series) was operated on as a 900-g premature infant in 1988. He was treated with multiple bronchoscopies for dilation of residual distal tracheal stenosis and removal of granulation tissue. Three years after the initial operation, he underwent redo pericardial tracheoplasty. $\mathrm{He}$ is alive today; however, he continues to require bronchoscopic intervention routinely. The second patient who required a redo tracheoplasty (no. 5 in the series) had a complex trachea. He initially underwent a costochondral graft to the cervical trachea, which was complicated by stenosis. This was followed 7 months later by anterior pericardial tracheoplasty. A redo tracheoplasty was performed 22 months later for persistent stenosis (Table 1).

There were a total of 5 deaths. There were 3 hospital deaths. The eighth patient in the series was a 10-monthold boy who underwent ventricular septal defect repair at an outside institution. His initial cardiac catheterization failed to diagnose a pulmonary artery sling. He presented to us with respiratory distress and was given a diagnosis of tracheal stenosis caused by complete tracheal rings. Anterior pericardial tracheoplasty was performed. A pulmonary artery sling was missed at the time of the operation. A subsequent echocardiogram and catheterization confirmed the presence of a pulmonary artery sling. This patient was reexplored and underwent anterior translocation of the left pulmonary artery in addition to resection of 4 tracheal rings (distal to the previous repair) with end-to-end anastomosis. At the time of re-exploration, the pericardial patch appeared to be intact, without need for revision. He died 5 weeks postoperatively of renal failure; his family declined dialysis. His airway was widely patent. 
TABLE 1. Associated anomalies and operations

\begin{tabular}{|c|c|c|c|c|c|c|}
\hline Patient no. & Age (mo) & No. of rings & Associated anomalies & Prior operations & Concomitant operations & Redo operations \\
\hline 1 & 6 & 5 & None & None & None & None \\
\hline 2 & 1 & 7 & $\begin{array}{l}\text { VSD, PDA, hyaline } \\
\text { membrane disease }\end{array}$ & ECMO & VSD/PDA repair & re-APT \\
\hline 3 & 4.5 & 8 & $\begin{array}{l}\text { VSD, PDA, anomalous } \\
\text { origin of right upper } \\
\text { bronchus, cerebral palsy }\end{array}$ & VSD/PDA repair & None & None \\
\hline 4 & 2.5 & 17 & $\begin{array}{l}\text { TOF, anomalous origin of } \\
\text { right upper bronchus }\end{array}$ & BTS & None & TOF repair \\
\hline 5 & 22 & 18 & BPD & Autologous rib grafting & None & re-APT pyloroplasty \\
\hline 6 & 2 & 8 & None & Bronchial stent insertion & None & None \\
\hline 7 & 22 & 8 & AS & None & Aortic valvotomy & None \\
\hline 8 & 10 & 22 & $\begin{array}{l}\text { VSD, PDA, vascular ring, } \\
\text { PA sling }\end{array}$ & $\begin{array}{l}\text { VSD/PDA/vascular ring } \\
\text { repair }\end{array}$ & re-APT, PA sling repair & \\
\hline 9 & 11 & 11 & None & None & None & None \\
\hline 10 & 2.5 & 12 & CAVC, Down's syndrome & PAB & None & CAVC repair \\
\hline 11 & 98 & 21 & PDA & PDA repair & None & None \\
\hline 12 & 7.5 & 21 & $\begin{array}{l}\text { PA sling, anomalous origin } \\
\text { of right upper bronchus }\end{array}$ & None & PA sling repair & None \\
\hline 13 & 2 & 18 & TOF, PA sling & Central shunt PA sling repair & None & TOF repair \\
\hline 14 & 8 & 14 & $\begin{array}{l}\text { ASD, PA sling, anomalous } \\
\text { origin of right upper } \\
\text { bronchus }\end{array}$ & None & ASD/PA sling repair & None \\
\hline 15 & 7 & 19 & ASD & None & ASD repair & None \\
\hline 16 & 0.25 & 20 & $\begin{array}{l}\text { PA sling, PDA, VATER } \\
\text { syndrome }\end{array}$ & Colostomy & PDA/PA sling repair & Tracheostomy \\
\hline 17 & 0.1 & 19 & $\begin{array}{l}\text { PDA, hyaline membrane } \\
\text { disease }\end{array}$ & None & PDA repair & None \\
\hline 18 & 1 & 6 & Tracheal web & $\begin{array}{l}\text { Laser incision of tracheal } \\
\text { web }\end{array}$ & None & None \\
\hline 19 & 6 & 7 & VSD, PDA & VSD/PDA repair & None & None \\
\hline 20 & 2 & 17 & $\begin{array}{l}\text { TOF, anomalous origin of } \\
\text { right upper bronchus }\end{array}$ & BTS & None & TOF repair \\
\hline 21 & 1 & 15 & $\begin{array}{l}\text { ASD, VSD, PDA, PA sling, } \\
\text { VATER syndrome }\end{array}$ & $\begin{array}{l}\text { Duodenostomy, Meckel's } \\
\text { excision }\end{array}$ & $\begin{array}{l}\text { ASD/VSD/PDA/PA sling } \\
\text { repair }\end{array}$ & None \\
\hline 22 & 22 & 18 & $\begin{array}{l}\text { ASD, VSD, LSVC, absent } \\
\text { of left lung, sequestration } \\
\text { medial segment of RLL }\end{array}$ & None & ASD/VSD repair & None \\
\hline 23 & 0.25 & 15 & $\begin{array}{l}\text { PDA, hypoplastic right lung, } \\
\text { skeletal anomalies, } \\
\text { subdural hematoma, } \\
\text { multicystic kidney }\end{array}$ & None & $\begin{array}{l}\text { PDA ligation, diaphragmatic } \\
\text { plication }\end{array}$ & Re-plication of diaphragm \\
\hline 24 & 1 & 17 & None & None & None & None \\
\hline 25 & 309 & 12 & $\begin{array}{l}\text { PA sling, LSVC, anomalous } \\
\text { origin of right upper } \\
\text { bronchus }\end{array}$ & Primary tracheal resection & PA sling repair & None \\
\hline 26 & 5 & 5 & $\begin{array}{l}\text { Anomalous origin of right } \\
\text { upper bronchus }\end{array}$ & None & None & None \\
\hline
\end{tabular}

$\overline{V S D}$, Ventricular septal defect; $P D A$, patent ductus arteriosus; $E C M O$, extracorporeal membrane oxygenation; $A P T$, anterior pericardial tracheoplasty; $T O F$, tetralogy of Fallot; $B T S$, Blalock-Taussig shunt; $B P D$, bronchopulmonary dysplasia; $A S$, aortic stenosis; $P A$, pulmonary artery; $C A V C$, complete atrioventricular canal; $P A B$, pulmonary artery banding; $A S D$, atrial septal defect; $V A T E R$, vertebrae, anus, trachea, esophagus, and renal; $L S V C$, left superior vena cava; $R L L$, right lower lobe.

The 22nd patient in the series was born with vertebrae, anus, trachea, esophagus, and renal (VATER) syndrome in addition to tracheal stenosis and multiple cardiac abnormalities. At 1 day old, he underwent duodenostomy and excision of Meckel's diverticulum. He underwent pericardial tracheoplasty with division of 15 tracheal rings at 1 week of age, at which time he also underwent concomitant repair of a ventricular septal defect, atrial septal defect, 
pulmonary artery sling, and division of a patent ductus arteriosus. Two weeks postoperatively, he was re-explored for a duodenal leak at the anastomotic site and subsequently died 2 months later of multisystem organ failure. His airway was widely patent.

The fifth patient in the series died 2 years postoperatively. He had been hospitalized since birth because of bronchopulmonary dysplasia and long-segment tracheal stenosis. He underwent a tracheostomy at 2 weeks of age at an outside institution. He was transferred to James Whitcomb Riley Hospital for Children at 17 months of age. He underwent an autologous rib graft tracheoplasty performed by the otolaryngology service. This was revised by a second rib graft 6 months later for tracheal stenosis distal to the rib graft. This was followed 2 months later by anterior pericardial tracheoplasty for residual intrathoracic tracheal stenosis. His postoperative course was complicated by frequent respiratory tract infections and repeated tracheal dilations. Two years later, after his first pericardial tracheoplasty, he underwent a second pericardial tracheoplasty. He died at home months later after a witnessed seizure. His airway at postmortem examination was widely patent, and the pericardial patch was well incorporated and covered with ciliated, pseudostratified columnar epithelium (Figures 4 and 5).

The 24th patient in the series was born with skeletal anomalies, including absent radii and ulnae, shortened humeri, subdural hematoma, multicystic kidneys, cleft palate, micrognathia, hypoplastic right lung, patent ductus arteriosus, diaphragmatic eventration, and tracheal stenosis. At 1 week of age, he underwent pericardial tracheoplasty with division of 15 rings, patent ductus arteriosus ligation, and right diaphragmatic plication. At 4 months of age, he underwent redo plication of the right hemidiaphragm for recurrent eventration. He had a protracted ventilator-dependent hospital course. Seven months postoperatively, the family wished to withdraw support. He died without evidence of tracheal stenosis.

The tenth patient in the series was born with Down's syndrome, seizure disorder, complete atrioventricular canal, and tracheal stenosis. At 2 months of age, pulmonary artery banding was performed. At 2.5 months of age, she underwent anterior pericardial tracheoplasty. At 2 years of age, she underwent atrioventricular canal repair with pulmonary artery patch angioplasty. She died at age 13 years suddenly and unexpectedly of a presumed arrhythmia. Of note, she did not experience respiratory difficulties before her last follow-up at age 10 years or preceding her death.

The diagnosis of tracheal stenosis is often made after stabilization of the patient's airway with mechanical ventilation. Nineteen $(73 \%)$ of 26 patients required intubation preoperatively, and 5 of those underwent tracheostomy preoperatively. This underscores the severity of tracheal stenosis. Referral for congenital tracheal stenosis is generally

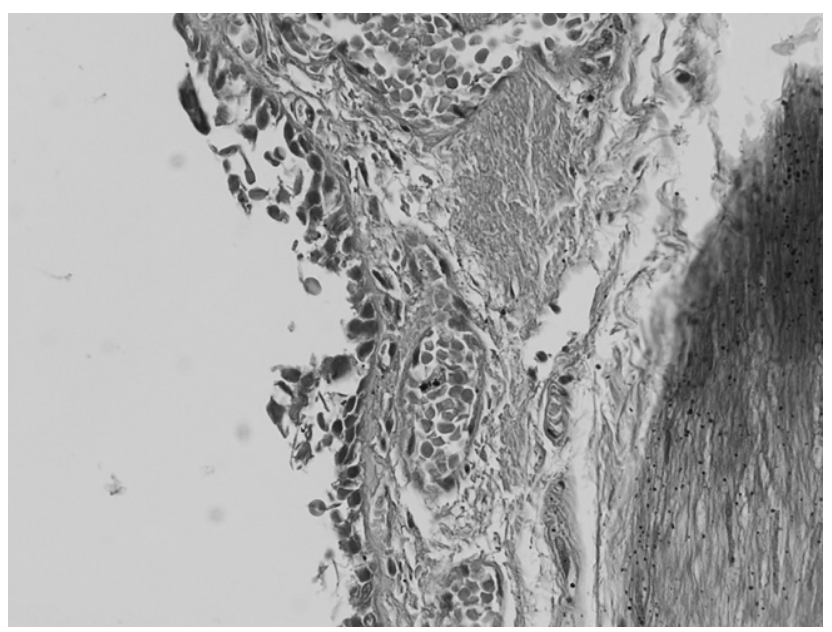

FIGURE 5. Biopsy specimen of the epithelium overlying granulation tissue at the site of the pericardial patch demonstrating ciliated pseudostratified columnar epithelium. (Hematoxylin and eosin stain; original magnification $40 \times$.)

made as soon as the diagnosis is made. In many cases the diagnosis of tracheal stenosis is not made at birth but after the treatment of respiratory insufficiency and the development of dependence on mechanical ventilation.

\section{DISCUSSION}

Pericardial tracheoplasty is a technically straightforward and safe procedure. After minimal tracheal dissection, the lateral blood supply of the trachea is not manipulated because there is no need to mobilize the circumference of the trachea, a technique that is required for other reconstructive procedures. Therefore there is theoretically a decreased risk of tracheal ischemia. The recurrent laryngeal nerves are less apt to injury. Long-segment stenoses that involve the mainstem bronchi are easily repaired. Pericardium is readily available, pliable, and easy to work with and maintain an airtight seal.

The mesenchymal tissue of the pericardium becomes covered with respiratory epithelium. The postmortem examination of patient 5 clearly demonstrates that the pericardial patch is well incorporated into the surrounding trachea and is unidentifiable in its original form. A complete lining of epithelium and development of normal mucosal and submucosal structures, including glands, and vessels were observed throughout the repaired trachea. As has also been described by Cheng and coworkers, ${ }^{6}$ the pericardial patch becomes well incorporated in as early as 3 months.

Long-segment tracheal stenosis, especially when involving the mainstem bronchi, is easily repaired by means of pericardial patch tracheoplasty. The long length of the stenosis makes reconstruction with the native trachea challenging. Slide tracheoplasty was initially proposed by Tsang and 
colleagues ${ }^{7}$ and modified by Grillo. ${ }^{8}$ In this technique the stenosis is transected at its midpoint. The 2 ends are spatulated by a longitudinal slit on the anterior surface of one end and the posterior surface of the other end. The spatulated ends are then advanced over one another and sutured together in an extended end-to-end fashion. This technique has proved to shorten intubation times because patients are typically extubated in the operating room. Subsequently, this also shortened hospital stays. Another advantage of slide tracheoplasty is the avoidance of graft material, the low rate of granulation tissue formation, and therefore the less frequent requirements for postoperative bronchoscopy. Tracheal reconstruction has been plagued by the frequent development of granulation tissue formation and postoperative tracheal stenosis. Although we have adopted the technique of avoiding the tracheal mucosa in the suture line, $10(38 \%)$ of 26 of the patients had some evidence of granulation tissue at postoperative bronchoscopic surveillance. Although this is more of a nuisance, 2 patients did require tracheostomy. One underwent tracheostomy 5 months postoperatively because of exuberant granulation tissue in addition to tracheal scarring below the level of the patch. The second patient underwent tracheostomy related to distal tracheal stenosis. The remaining 8 patients were treated with a single procedure and did not exhibit any future evidence of airway obstruction or granulation tissue.

Repair with tracheal autograft has emerged as a new technique to treat long-segment congenital tracheal stenosis. This technique, however, does not always solely address the length of the stenosis. In a series of 9 patients who underwent repair by means of tracheal autograft, 5 of these patients required augmentation with a pericardial patch. Furthermore, 1 case was complicated by autograft dehiscence, a problem not seen in our series with the pericardial patch. $^{9-11}$

In contrast to techniques that involve reconstruction of the native trachea, neither the length nor the location of the stenosis is a technical limitation to anterior pericardial tracheoplasty. The pericardial patch has been used to treat stenoses that extend to the mainstem bronchi; reconstruction of the native airway can become complicated when the bronchus is involved.

The mortality rate of pericardial patch tracheoplasty is comparable with that of other techniques. This is reflective of the finding that tracheal stenosis is commonly associated with other severe defects and their attendant morbidities. In this series, of the 5 patients who died, 4 also had other complex intracardiac abnormalities, and 1 patient had severe bronchopulmonary dysplasia. The highest mortality rate observed after surgical repair of congenital tracheal stenosis is observed in patients younger than 1 month and those with intracardiac anomalies. ${ }^{12}$

Limitations to this study include the small number of patients. Congenital tracheal stenosis is notably a rare disease. The few studies that do address this problem are limited by the number of patients. In addition, this study is limited as a retrospective chart review. Therefore objective data, such as postoperative tracheal diameter, and data from functional studies, such as spirometry, were not obtained routinely. Also, a few patients were lost to follow-up.

In summary, anterior pericardial tracheoplasty is an attractive therapeutic option for small infants and children with long-segment tracheal stenosis. Major advantages to this technique include (1) no restrictions for a patient's age and size, (2) no technical limitations based on the length and location of the stenosis, and (3) the possibility of concomitant repair of cardiac lesions. The majority of survivors in this series remain asymptomatic and enjoy a good quality of life.

\section{References}

1. Benjamin B, Pitkin J, Cohen D. Congenital tracheal stenosis. Ann Otol Rhinol Laryngol. 1981;90:364-71.

2. Kimura K, Mukohara N, Tsugawa C, Matsumoto Y, Sugimura C, Murata H, et al. Tracheoplasty for congenital stenosis of entire trachea. J Pediatr Surg. 1982;17: 869-71.

3. Idriss FS, DeLeon SY, Ilbawi MN, Gerson CR, Tucker GF, Holinger L. Tracheoplasty with pericardial patch for extensive tracheal stenosis in infants and children. J Thorac Cardiovasc Surg. 1984;88:527-36.

4. Bando K, Turrentine MW, Sun K, Sharp TG, Matt B, Karmazyn B, et al. Anterior pericardial tracheoplasty for congenital tracheal stenosis: intermediate to longterm outcomes. Ann Thorac Surg. 1994;120:1363-9.

5. Menu Y, Lallemand D. Determination of the normal transverse diameter of the trachea in childhood. Ann Radiol. 1981;24:73-5.

6. Cheng A, Backer C, Holinger L, Dunham M, Mavroudis C, Gonzalez-Crussi F. Histopathologic changes after pericardial patch tracheoplasty. Arch Otolaryngol Head Neck Surg. 1997;123:1069-72.

7. Tsang V, Murday A, Gillbe C, Goldstraw P. Slide tracheoplasty for congenital funnel-shaped tracheal stenosis. Ann Thorac Surg. 1989;48:632-5.

8. Grillo HC. Slide tracheoplasty for long-segment congenital tracheal stenosis. Ann Thorac Surg. 1994;58:613-21.

9. Backer C, Mavroudis C, Dunham M, Holinger L. Intermediate-term results of the free tracheal autograft for long segment congenital tracheal stenosis. J Pediatr Surg. 2000;35:813-9.

10. Backer C, Holinger L, Mavroudis C. Congenital tracheal stenosis: tracheal autograft technique. Operative Techniques Thorac Cardiovasc Surg. 2007;12: 178-83.

11. Backer C, Holinger L, Mavroudis C. Repair of congenital tracheal stenosis. Semin Thorac Cardiovasc Surg Pediatr Card Surg Annu. 2002;5:173-86.

12. Chiu P, Kim P. Prognostic factors in the surgical treatment of congenital tracheal stenosis: a multicenter analysis of the literature. J Pediatr Surg. 2006; 41:221-5.

\section{Discussion}

Dr Gordon Cohen (Seattle, Wash). I want to thank the association for the opportunity to discuss this important article by $\mathrm{Dr}$ Fanous. The article is another example of excellent work done by Dr John Brown and his group at Indiana University.

This article reports the long-term follow-up of their experience treating congenital tracheal stenosis with anterior pericardial tracheoplasty over a 22-year period. Congenital tracheal stenosis is a very complex problem, and the surgical approach to this entity varies from center to center. Although numerous surgical procedures have been described, there is no clear consensus on the best surgical treatment for this condition. The reason for the lack 
of unity is likely the rare nature of the condition itself and the absence of any long-term follow-up for any given technique. The article presented today by Dr Fanous provides us with some insight into the long-term outcomes of one of the more widely used techniques: anterior pericardial tracheoplasty.

Dr Fanous, I have a few questions for you today, and I will give you the opportunity to answer each one as I go so you do not have to remember all this.

One of the common problems associated with anterior pericardial tracheoplasty is the formation of granulation tissue within the tracheal lumen. The granulations themselves can be extremely problematic. The incidence of this problem is quite high; in fact, you reported it to be as high as $38 \%$ in your series. Given the high incidence and the potential of severity of these granulations, do you have a surveillance protocol to look for granulation tissue, and if so, what does that protocol involve, and how do handle the granulations when you find them?

Dr Fanous. Thank you very much. Our patients are usually intubated from 1 week to 14 days postoperatively. Before extubation, they undergo bronchoscoipc evaluation, and at that time, if the patient's airway is otherwise intact without granulation tissue, then we proceed down the extubation pathway. Bronchoscopy is not done routinely after extubation unless there are other respiratory or airway symptoms. Of the 10 patients who did have granulation tissue in our series, 1 had exuberant granulation tissue combined with stenosis and did go on to require tracheostomy. The other 9 patients were all dealt with through bronchoscopic removal of the granulation tissue. Therefore we saw that more as a nuisance rather than a devastating complication.

Dr Cohen. And long-term, did you see any granulations and have any need for ....

Dr Fanous. There is 1 patient. One of our patients who still has a tracheostomy to this day and has granulation tissue that still requires removal periodically.

Dr Cohen. Some centers use slide tracheoplasty as their preferred surgical approach for the treatment of congenital tracheal stenosis. The benefit to slide tracheoplasty is that you reduce the formation of granulations, and you have early extubation. Does your center have any experience with alternate techniques, such as slide tracheoplasty, and if so, what would have been your results with that procedure? In addition, if you have these multiple techniques, what has been your algorithm for deciding which surgical approach to take?

Dr Fanous. We do, in fact, most commonly use the anterior pericardial tracheoplasty for these patients. There have been a handful of patients who have undergone slide tracheoplasty, and we find that when the stenoses are of very long segments-and 1 patient had up to 22 rings - it is technically easier to use the pericardial patch. Although we do acknowledge that the granulation tissue is limited with the use of slide tracheoplasty and the patients are extubated earlier, sometimes in the operating room postoperatively we do not use it because our experience has been mostly with pericardial tracheoplasty.

Dr Cohen. In those patients in whom you decided to do a slide tracheoplasty, is there a cutoff for a certain number of complete tracheal rings that you would use to make that decision?

Dr Fanous. For a long segment, greater than 5 or 6 rings, we go to a pericardial tracheoplasty.
Dr Cohen. As a follow-up to that question, in your hands anterior pericardial tracheoplasty seems to have a relatively low operative mortality. However, in the meta-analysis that you showed, tracheal resection, which is not always possible, followed by slide tracheoplasty had a much lower operative mortality than pericardial tracheoplasty. Again, given the lower incidence of complications and the lower mortality, should we as a field not adopt slide tracheoplasty as a preferred treatment method when it is technically possible? Do you have an opinion on that?

Dr Fanous. If slide tracheoplasty has good outcome in the surgeon's hands and the surgeon is confident in performing that technique and there is not a long length of stenosis, I think that is very acceptable.

Dr Cohen. Finally, I have a technical question. In your article you describe harvesting fresh pericardium. Do you use the pericardium in the untreated state, or do you treat it with glutaraldehyde? If you use it fresh, have you had any problems with early shrinkage of the patch requiring reintervention?

Dr Fanous. The patch is used as a fresh patch. Our thought behind that is that we prefer to put in living tissue as a bed for future growth and future vascularization. We do believe that there is some shrinkage of the patch, and that is the reason why we enlarge the proposed diameter to greater than $1 \frac{1 / 2}{2}$ times normal as adjusted for age and size.

Dr Cohen. Drs Fanous and Brown, congratulations on your excellent success with this complex group of patients. Your report of longterm outcomes is an important addition to our body of knowledge.

Thanks again to the association for the opportunity to discuss this article.

Dr Douglas Wood (Seattle, Wash). I congratulate you on your outcomes, but I am going to push a little farther with Dr Cohen's questions and criticisms. I think that in the ear, nose, and throat literature and in the thoracic surgery literature in general, tracheoplasty procedures have not been shown to have as durable a result as tracheal resection and use of the native trachea in reconstruction. It is easy to understand why. One is taking a dead piece of tissue and putting it in part of the trachea to augment the trachea in an environment that is chronically contaminated; it is no wonder that there will be chronic granulation tissue and that healing can only occur really by means of contracture and fibrosis. It is actually encouraging that in spite of this, a number of patients can end up having good outcomes. Yet there is now a better technique, a technique of slide tracheoplasty that does suffice for a full segment of tracheal stenosis and allows the use of the native trachea to augment the trachea with better outcomes, as shown by Dr Backer and his colleagues in Chicago. I think that your results are very good, but I guess I would allege that when one looks at the results in airway surgery, there would still be a pressure to move forward to evolving to slide tracheoplasty for the vast majority of patients rather than augmentation tracheoplasty.

Dr Fanous. Thank you. Although we do acknowledge that use of the native trachea for a tracheal reconstruction is ideal, in many situations it is not possible because of long length, and sometimes the tracheal stenosis involves one of the mainstem bronchi or even a trifurcation of the trachea. In those cases reconstruction through the slide tracheoplasty technique can be very difficult. In addition, many of these patients have congenital cardiac malformations that require repair at the time of the tracheoplasty. In this situation the 
patients are already undergoing cardiopulmonary bypass, which might not be necessary for slide tracheoplasty, and therefore in essence it can kill 2 birds with 1 stone.

Dr Wood. I respectfully disagree. I think slide tracheoplasty is effective for even long-segment tracheal stenosis. Its very design is to be able to accomplish that. At least in the pediatric population, my understanding is that almost all of these are done during cardiopulmonary bypass through the same anterior approach and with the same ability to correct congenital cardiac defects at the same time.

Dr Fanous. My understanding is that there are some groups that perform slide tracheoplasty without the use of cardiopulmonary bypass. We are not saying that pericardial tracheoplasty is a better option, but we are saying that it is safe and is a durable option with good long-term outcomes. Slide tracheoplasty and tracheal autograft are also good techniques. 